This item was submitted to Loughborough's Research Repository by the author.

Items in Figshare are protected by copyright, with all rights reserved, unless otherwise indicated.

\title{
A model for weld strength in ultrasonically consolidated components
}

PLEASE CITE THE PUBLISHED VERSION

PUBLISHER

Professional Engineering Publishing / @ IMechE

VERSION

VoR (Version of Record)

LICENCE

CC BY-NC-ND 4.0

REPOSITORY RECORD

Kong, Choon-Yen, Rupert C. Soar, and Phill M. Dickens. 2019. "A Model for Weld Strength in Ultrasonically Consolidated Components". figshare. https://hdl.handle.net/2134/4714. 
This item was submitted to Loughborough's Institutional Repository (https://dspace.lboro.ac.uk/) by the author and is made available under the following Creative Commons Licence conditions.

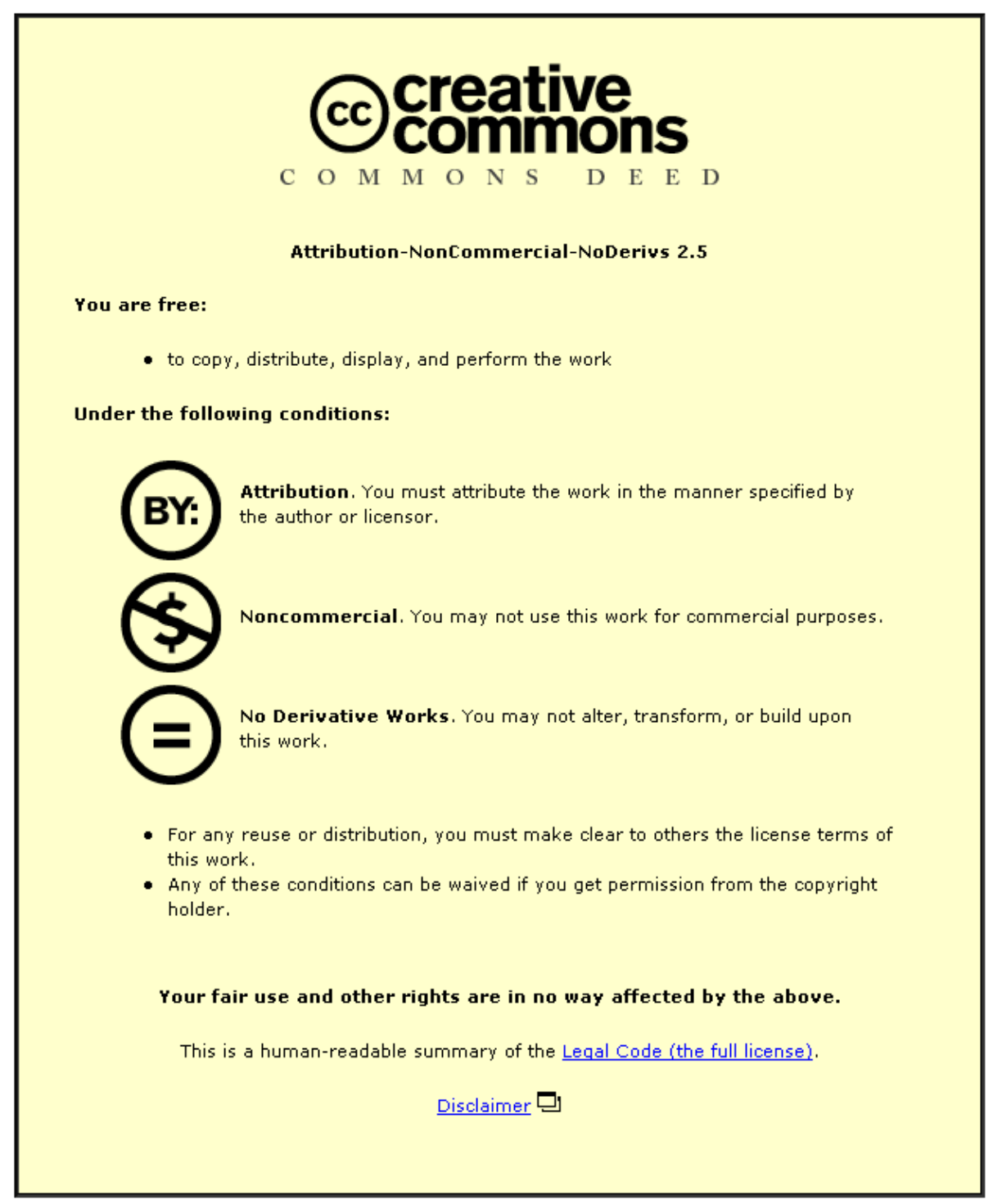

For the full text of this licence, please go to: http://creativecommons.org/licenses/by-nc-nd/2.5/ 


\title{
A model for weld strength in ultrasonically consolidated components
}

\section{Y Kong*, R C Soar, and P M Dickens}

Rapid Manufacturing Research Group, Wolfson School of Mechanical and Manufacturing Engineering, Loughborough University, Loughborough, UK

The manuscript was received on 15 January 2004 and was accepted after revision for publication on 8 October 2004.

DOI: 10.1243/095440605X8315

\begin{abstract}
Ultrasonic consolidation (UC) is a solid freeform fabrication technique developed for the manufacture of metal parts. The mechanisms by which bonds are formed, during the UC process, are based on a combination of the surface effect and the volume effect. Based on the outcomes of peel tests and microstructural analysis, this paper will consider the influence of these two phenomena on the weld strength of specimens. A model is presented to describe how calculations for weld strength may be derived on the basis of the theory of surface and volume effects. Through the application of the model, it was possible to demonstrate that the weld strength may be 7 per cent greater than the tensile strength of the base metal. The identification of the phenomena and the development of a model for weld strength have led to the modification and production of an enhanced test procedure which is described in this paper.
\end{abstract}

Keywords: layered manufacturing, weld strength, solid state welding, aluminium alloy, ultrasonic consolidation

\section{INTRODUCTION}

The ultrasonic consolidation (UC) process is a proprietary process based on rapid prototyping and rapid tooling fabrication techniques that is capable of overcoming some of the issues associated with freeform laser fusion techniques [1]. The basic principles for the UC process and conventional ultrasonic seam welding are similar. However, the UC process involves the application of ultrasonic oscillatory energy sequentially to weld layers of metal foil to one another, during which the profile of each layer is created by a contour milling operation, whereas ultrasonic seam welding is generally used to join two overlapped sheets. The UC process produces metal components and tooling and is currently being developed as a promising technique to produce functionally graded structures, metal matrix composites, and fibre-embedded adaptive structures. The identification of a weld strength model will help

\footnotetext{
*Corresponding author: Rapid Manufacturing Research Group, Wolfson School of Mechanical and Manufacturing Engineering, Loughborough University, Loughborough LE11 3TU, UK.
}

to control the mechanical properties in fabricating components and also feed into the ongoing experiments on adaptive composite fabrication and ultrasonic cladding/skinning of metal structures.

\section{BACKGROUND TO ULTRASONIC CONSOLIDATION}

The UC machine used was derived from a modified $3.3 \mathrm{~kW}$ seam welding apparatus operated at a constant $20 \mathrm{kHz}$ frequency. During the welding process, the transducer-booster-sonotrode stack rotates counterclockwise, at a predefined speed, while ocillating transversely to the direction of the weld (see Fig. 1). A constant load or 'contact pressure' is applied to the sonotrode to generate a highly 'localized' scrubbing action at the mating surfaces of the workpieces. This action breaks up surface contaminants and oxides to permit metal-metal contact $[2,3]$ at regions within the weld interface (termed 'contact points'). As welding continues, the scrubbing action produces elastic-plastic deformation, within the weld interface, across which diffusion 

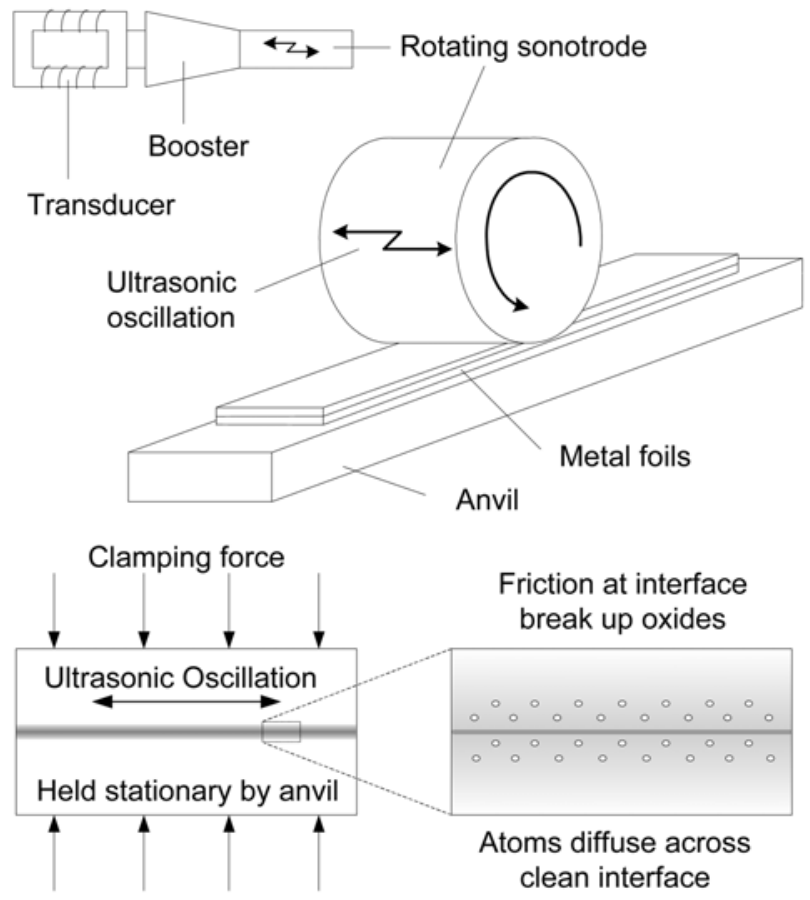

Fig. 1 Basic principle of ultrasonic consolidation

and plastic flow take place [4]. Depending on the traverse speed of the sonotrode, oxides and surface contaminants continue to break up and may be displaced within the vicinity of the interface and along the weld zone $[\mathbf{5 , 6}]$ resulting in solid-state metallurgical bonds and no noticeable external deformation of the specimen $[\mathbf{7}, \mathbf{8}]$.

Within the UC process, as with all ultrasonic processes, there are three control parameters: amplitude of oscillatory displacement, contact pressure, and weld speed. Under ultrasonic oscillation the sonotrode reciprocates longitudinally along its axis in the range of around $6.5-14.5 \mu \mathrm{m}$. The contact pressure, ranging from 0 to $690 \mathrm{kPa}$, ensures intimate contact between the workpieces. The third variable is the sonotrode traverse speed (or weld speed) which has a range from static to $77 \mathrm{~mm} / \mathrm{s}$.

\section{CHARACTERIZATION OF THE UC PROCESS}

Initial research, described in previous publications $[\mathbf{9}, \mathbf{1 0}]$, centred on the identification of the optimum combination of process variables to produce welds in 3003 and 6061 alloys. The model of weld strength described in this paper is based on the results obtained with the 6061 alloy specimens produced.

In the experiment, annealed aluminium 6061 foils of $25 \mathrm{~mm}$ width and $100 \mu \mathrm{m}$ thickness were used as this is the standard size for foils used in this and other commercial UC equipment. Thin foil will ensure high accuracy, as well as better resolution of the built component. Thicker foils can be used for faster build-up times, but this must be balanced by a possible reduction in bond efficiency owing to insufficient ultrasonic energy being delivered to the material to create metallurgical bonds. The 6061 foils were surface cleaned with degreaser (petroleum distillate) and wiped with a soft cotton cloth to remove any oil, friable oxide, and contaminant. The reason for the surface preparation procedure was because of the presence of a distinctive oxide layer predominantly of, magnesium oxide (MgO) interspersed with aluminium oxide $\left(\mathrm{Al}_{2} \mathrm{O}_{3}\right)$. The resultant $\mathrm{MgO}$ oxide layer was powdery in appearance and friable, with a thinner $\mathrm{Al}_{2} \mathrm{O}_{3}$ layer beneath it $[\mathbf{1 1}, \mathbf{1 2}]$. During welding, the UC process was incapable of dispersing the $\mathrm{MgO}$ layer, which tended to shear readily, compared with the underlying $\mathrm{Al}_{2} \mathrm{O}_{3}$ and bulk metal, resulting in slip and energy absorption between the two mating surfaces $[13,14]$.

\subsection{Peel test}

Peel tests were performed to determine the weld quality, based on the average resistance to peeling, of the contact points within the weld interface. Generally, as the number and size of contact points increased, so did resistance to peeling. Peel test specimens were prepared by first cladding a single layer of 6061 foil to an aluminium 1050 supporting plate $(28 \mathrm{~mm}$ wide $\times 150 \mathrm{~mm}$ long $\times 1.2 \mathrm{~mm}$ thick $)$ and followed by second layer of foil. The free length of 6061 foil used to load the joint was $100 \pm 5 \mathrm{~mm}$ and was attached to a standard tensile test machine. Loads were applied to the second foil, as shown in Fig. 2a, at a pulling speed of $50 \mathrm{~mm} / \mathrm{min}$.

Figure $2 \mathrm{~b}$ shows the peeling load data for specimens welded at various process parameter settings. Amplitudes at 6.8, 10.4, and $14.3 \mu \mathrm{m}$ represent the minimum, medium, and maximum amplitude of the UC equipment. From the results it was observed that, for specimens produced at high contact pressures $(>241 \mathrm{kPa})$ and slow weld speeds $(<34.5 \mathrm{~mm} / \mathrm{s})$, the specimens failed through a mode I crack-like geometry (tensile failure) at the beginning of the weld region, at around $71.7 \mathrm{~N}$, and represented failure in the single foil and not the welded region. For this research this figure was termed the "critical peeling load'. Specimens that failed at loads below the critical peeling load produced tears within the weld region, propagating from the various contact points.

The inability of the peel test to indicate weld strength above the critical peeling load was therefore an indication of its limitation, as it could only measure weld strength up to the point where failure occurred in the base metal foil, whereas weld 

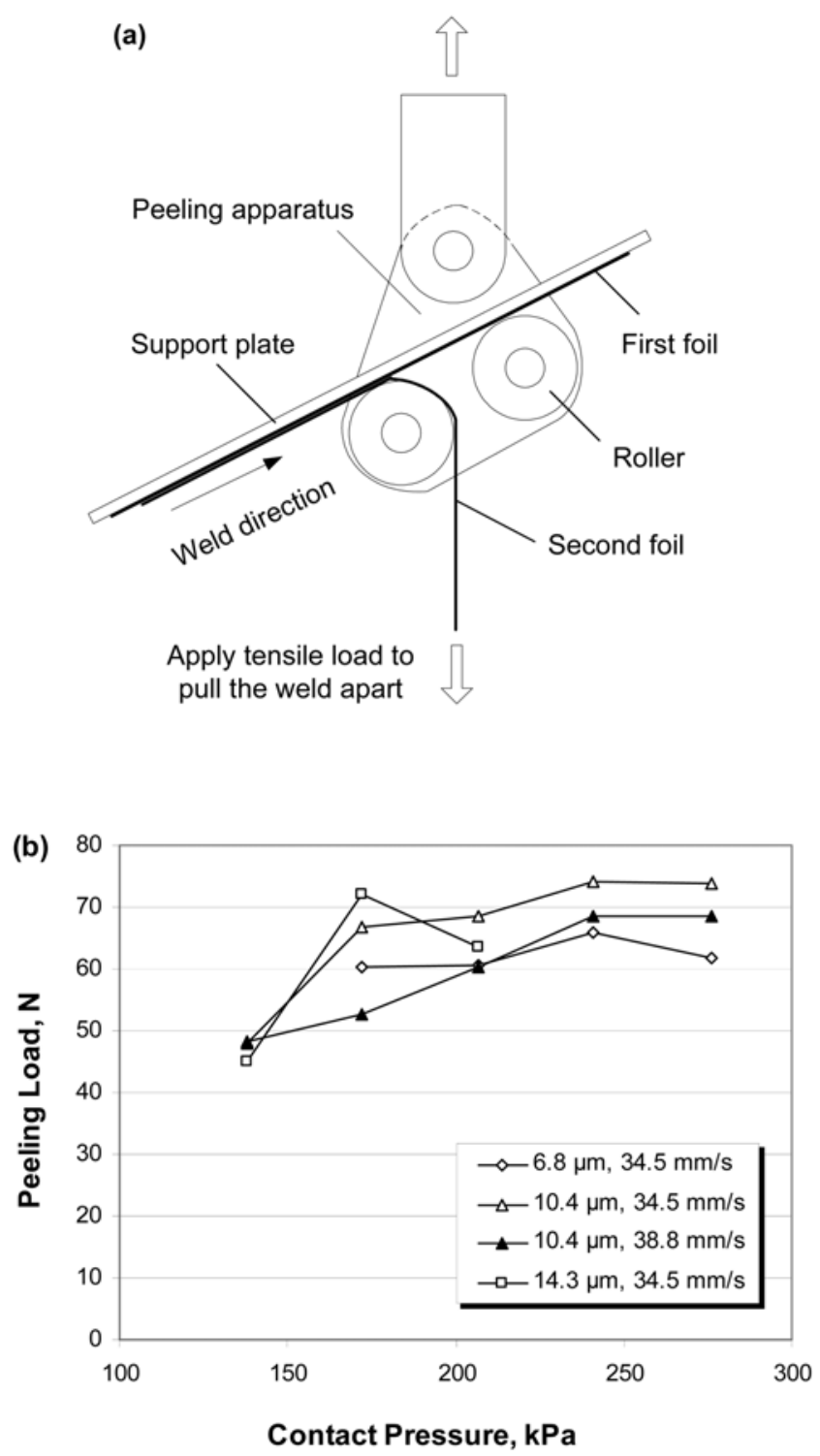

Fig. 2 (a) Peeling test apparatus showing specimen support and (b) peeling load versus contact pressure of 6061 alloy specimens welded for each combination of contact pressures and amplitude settings

strength within the weld interface may well increase beyond this point. It was only through microstructural analysis that significant differences began to show.

\subsection{Microstructural analysis}

A microstructural procedure was established to analyse the weld interface between the two welded strips of foil. For this analysis, the 'linear weld density', $\alpha$, was used to represent the percentage of contact points showing diffusion (i.e. the real contact area), $A_{\mathrm{r}}$, as a proportion of the sample area of the weld interface studied (i.e. the apparent welded region), $A_{\mathrm{p}}$, and was expressed as

$$
\alpha=\frac{A_{\mathrm{r}}}{A_{\mathrm{p}}} \times 100 \%
$$

From each of the three welded specimens prepared, for any combination of control parameters, three samples were cut from the beginning, centre, and end of the weld region. These were mounted, polished, and etched with Keller's solution, before being examined under a $\times 200$ optical microscope. Parameters $A_{\mathrm{r}}$ and $A_{\mathrm{p}}$ were measured by taking physical measurements from micrograph images of the weld cross-sections of the specimens.

From these measurements, an average linear weld density of up to 45 per cent was recorded. This figure would be expected to increase further if, say, a chemical etching operation were employed prior to welding. Figure 3 shows the average linear weld density of the specimens produced at incremental contact pressures ranging from 138 to $276 \mathrm{kPa}$. The figure shows a consistent increase in the number and proportion of contact points within the weld interface as welding parameters increase (or decrease in the case of weld speed). Figure 4 presents an SEM micrograph of the weld interface, showing a discontinuous oxide layer and visible contact points between the foil base metals.

Comparing the microstructural data with the peel test results in Fig. $2 b$, the data from the two graphs appear to 'track' up to the 'critical peeling load'. Beyond this point, the microstructural data indicate that weld strength may be increasing (whereas the peel test data level off) beyond the point at which the foils were failing in the peel test. At that stage, however, the microstructural data could not be

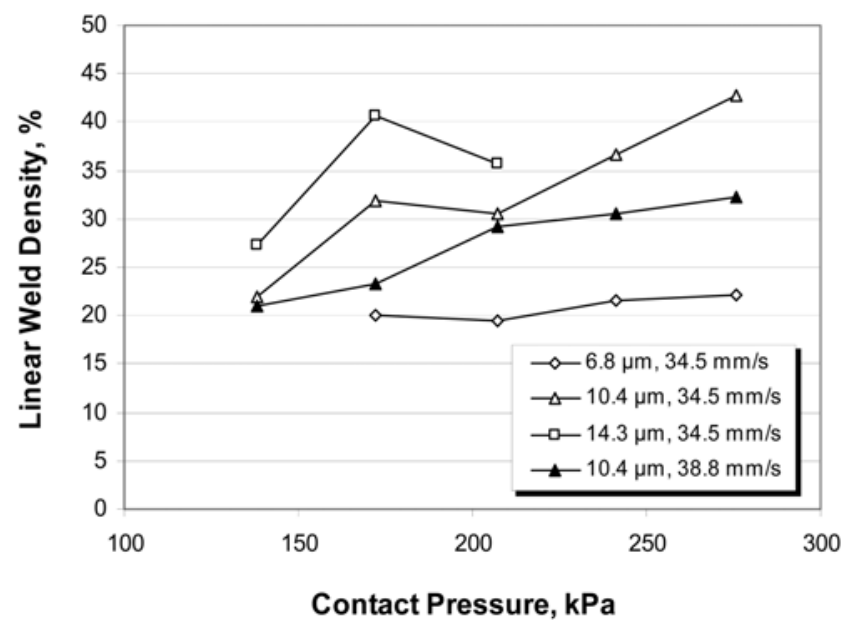

Fig. 3 Linear weld density of specimens welded for each combination of process variables 


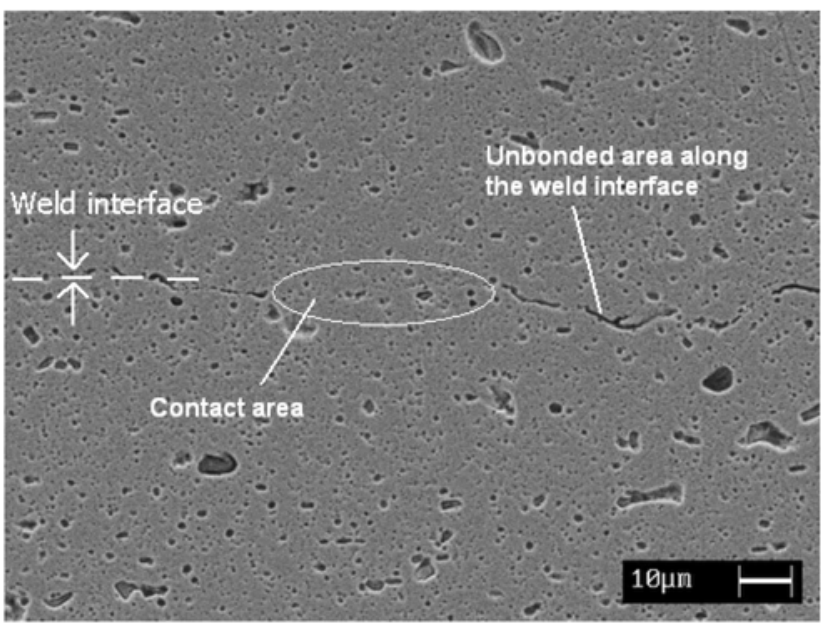

Fig. 4 Cross-section of the 6061 alloy specimen, showing the weld interface with contact points and oxides dispersed along the interface

correlated directly with the peel test data, as the microstructural analysis data were, essentially, statistical measures from sampled points within the weld interface. The next stage of the research was therefore to identify how these datasets could be correlated, and this was done by understanding how ultrasonic welds, and ultimately weld strength, are formed during the consolidation process.

\section{THEORY OF SURFACE AND VOLUME EFFECT}

When discussing ultrasonic welding in metal joints, weld strength is derived from two phenomena, namely the 'surface effect' and the 'volume effect' [15-19]. The surface effect describes the interfacial friction between the two mating surfaces, while the volume effect concerns the internal stresses and plastic deformation within the metal during welding. Most ultrasonic welding operations are governed by the surface effect where, under oscillatory vibration, the friction and bonding mechanisms are a function of applied forces, the surface topography, the nature of the oxide film, and the relative hardness of the oxide and its underlying metal $[\mathbf{2 0}, \mathbf{2 1}]$. Less is known of the volume effect, as it does not directly affect conventional welding operations. What differentiates the UC process from traditional ultrasonic metal welding operations is the exploitation of plastic flow within the metal foils (owing to the volume effect). This mechanism allows the embedding of delicate active/passive fibre elements and components within a three-dimensional metal structure as they are fabricated. Prior research has shown that ultrasonic energy enhances the plastic deformation of metals during metal working owing to a combination of dislocation generation, mobility, and interaction processes [15-18, 22], and, although a number of publications have reported both surface and volume effects in ultrasonic metal working, the mechanism describing these effects, when applied to the UC process, has not been fully explained.

\subsection{Surface effect}

Before discussing friction and bonding mechanisms, it must first be understood how the surface film, in particular the oxide layer, influences weld formation. For most aluminium alloy foils, the oxide present on the surface is $\mathrm{Al}_{2} \mathrm{O}_{3}$, the properties of which do not affect weld quality in ultrasonically welded specimens owing to its inherent brittle characteristics. As welding proceeds, the oxide layer is 'scrubbed' against that of its neighbour, which effectively shatters and disperses it. The effect is enhanced by plastic flow (volume effect) set up within the base metal, beneath the oxide layer, which assists this process through surface buckling (elastic-plastic deformation) [2].

The friction and bonding mechanisms that take place during ultrasonic welding may be explained by friction theory. Of the many theories that exist, it is the present authors' opinion that the 'stickslip phenomena' [23] may best describe the bonding mechanism during ultrasonic welding. Under ultrasonic excitation, the sonotrode vibrates transversely to the direction of welding and creates friction to the mating faces of the workpieces. Asperities on the opposite surfaces of the work pieces shear over each other, where bonding between asperities (stick) and destruction of contact points (slip) occur $[4,19,22,24]$. During the stick phase of the bonding process there may be mechanical interlocking or chemical bonding within the contact points, leading to diffusion of atoms across the weld interface and, therefore, a growth in the weld strength. The slip phase, which follows the stick phase, leads to a breakaway of the contact points and a rapid sliding motion, or displacement. As sliding continues, surface deformation increases, the oxide film is displaced, and contact points increase in both number and cross-sectional area until the stick phase re-establishes itself. The continuous formation and breakdown of contact points, during welding, produces strain hardening at the weld interface which may increase the weld strength of the specimen.

\subsection{Volume effect}

The volume effect occurs when ultrasonic energy absorbed into the dislocations increases the mobility 
of dislocations within the crystal lattice $[\mathbf{1 7}, \mathbf{2 2}, \mathbf{2 5}]$. During plastic deformation, high resistance stresses (or static yield stresses) are produced within the material owing to the obstacles, such as grain boundaries, imperfections, etc., that block dislocation movement. Where additional energy (i.e. additional forces generated through thermal energy or, in the present case, ultrasonic energy) is available to free the dislocations, then dislocation-obstacle interaction forces are relatively low, resulting in the metal being deformed at relatively low stresses. This phenomenon, during ultrasonic excitation, was reported by Langenecker [22] as an 'acoustic softening' effect.

By superimposing ultrasonic energy and contact pressure (static normal force), large numbers of dislocations may then overcome any existing resistance to deformation, resulting in large plastic deformation at the weld interface. The resultant plastic deformation, when combined with the surface friction mechanism, breaks up the oxide layer and enhances contact point initiation and growth, which increases the linear weld density. Moreover, as high-intensity ultrasonic energy is used in the UC process, there is an increase in dislocation density owing to the production of new dislocations [17]. Since the weld interface has more grain boundaries and imperfections, which are barriers to the development of plastic deformation, the greatest accumulation of dislocations will be found in and around the contact points. Mechanisms for dislocation 'pile-up' were studied by Langenecker [22], using ultrasonic assisted tensile testing and electronic microscopic analysis, and this phenomenon was known as 'acoustic hardening'. Relating these mechanisms to the research may explain why the welds produced had higher strength after ultrasonic welding by comparison with the base metal.

\section{DETERMINATION OF WELD STRENGTH}

\subsection{Limitations of the peel test for predicting increasing weld strength}

From the peel tests performed it was stated that, as the 'critical peeling load' was exceeded, the specimens failed in the base metal adjacent to the weld region, and not in the weld region itself. The implication was that, for specimens with sufficient weld strength, the weld could resist greater peeling loads than the base metal, with the effect being seen as a 'levelling off' of the peeling load data as failure occurred in the base metal adjacent to the weld.

The theory of surface and volume effects has shown how weld strength may be greater than the strength of the base metal. Essentially, the levelling off seen in the peel test data was an indication of the limitation of the test when estimating weld strength, as it could not indicate by how much the strength of the weld had increased beyond the strength of the base metal. It was therefore important to identify a method for calculating increasing weld strength above the 'critical peeling load'.

\subsection{Theoretical model for weld strength}

As stated, strain hardening and acoustic hardening in the weld interface meant that weld strength should continue to increase, as amplitude and contact pressure increase and weld speed decreases, beyond the critical peeling load. It was possible to show an increase in weld strength and produce a model to describe this process by, essentially, superimposing the microstructural analysis data (linear weld density) onto the peel test data, as shown in Fig. 5.

The relationship between failure of the weld during the peel test and its strength, $\sigma_{\mathrm{w}}$, was drawn upon to produce two equations that describe failure below, at, or above the critical peeling load

$$
\begin{array}{ll}
F<F_{\mathrm{w}, \text { crit }}, & \sigma_{\mathrm{w}}=\frac{F_{\mathrm{w}}}{A_{\mathrm{w}}} \\
F>F_{\mathrm{w}, \text { crit }}, & \sigma_{\mathrm{w}}=\frac{F_{\mathrm{w}, \text { crit }}}{A_{\mathrm{w}}} \frac{\alpha}{\alpha_{\text {crit }}}
\end{array}
$$

where $F_{\mathrm{w}}$ is the peeling load obtained from the peel test, $F_{\mathrm{w}, \text { crit }}$ is the critical peeling load defined by a sharp clean break produced in the base metal adjacent to the weld region, $A_{\mathrm{w}}$ is the predicted 'effective

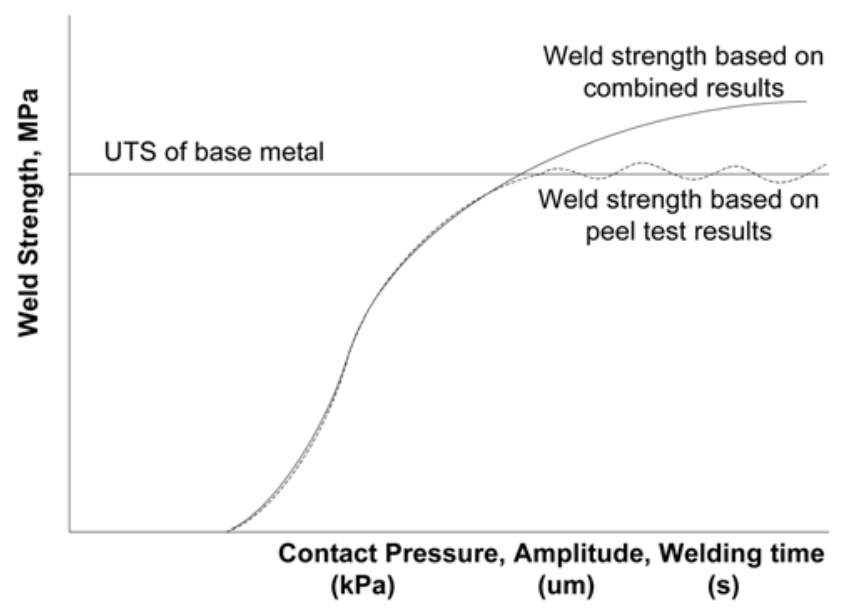

Fig. 5 Theoretical model showing the difference in weld strength plotted using peel test results and the combination of peel test data and linear weld density 
load-bearing area' which is defined as a very thin area, within the weld region, comprising bonded and unbonded areas, and $\alpha_{\text {crit }}$ is the linear weld density at the critical peeling load ( $\alpha_{\text {crit }}=38.8$ per cent).

Calculation of $A_{\mathrm{w}}$ was based upon prior research by Madaah-Hosseini and Kokabi [26] who quantified weld strength using both peel test data and the $A_{\mathrm{w}}$. To apply this work to UC successfully it was necessary to identify an effective calculation of $A_{\mathrm{w}}$ owing to the differences in the forces used in the present research and the research by Madaah-Hosseini and Kokabi. In Madaah-Hosseini and Kokabi's research, the calculation for $A_{\mathrm{w}}$ was based on cold rolling equipment capable of producing up to 80 per cent deformation in the two surfaces being bonded. This would not be the case for the UC research owing to the lower contact pressures used.

To identify $A_{\mathrm{w}}$, the formulae

$$
\sigma_{\mathrm{w}, \text { crit }}=\frac{F_{\mathrm{w}, \text { crit }}}{A_{\mathrm{w}}} \quad \text { and } \quad \sigma_{\mathrm{w}, \text { crit }}=\sigma_{\mathrm{m}}
$$

are considered, where $\sigma_{\mathrm{w}}$, crit is the critical weld strength and $\sigma_{\mathrm{m}}$ is the strength of the base metal. To solve equation (3), the effect of strain hardening [25]

$$
\sigma_{\mathrm{m}}=K(\varepsilon)^{n}
$$

must be considered, where $K$ is the stress at unit strain $(K=224 \mathrm{MPa})$ and $n$ is the strain hardening exponent ( $n=0.209$ ) for 6061-T0 alloy foil [27], and $\varepsilon$ is the true strain. At room temperature, the strength of the 6061 foil, under tensile loading, was $115 \mathrm{MPa}$, and therefore the strain $\varepsilon=0.041$.

As the critical weld strength was $\sigma_{\mathrm{w} \text {, crit }}=\sigma_{\mathrm{m}}=$ $K(\varepsilon)^{n}$ and the critical peeling load, drawn from the peel test data, was $71.7 \mathrm{~N}$, then within the weld interface

$$
A_{\mathrm{w}}=\frac{F_{\mathrm{w}, \mathrm{crit}}}{K(\varepsilon)^{n}}
$$

was $0.624 \mathrm{~mm}^{2} ; A_{\mathrm{w}}$ was assumed to be constant in this model, as the testing procedure for all peel test specimens was identical.

\subsection{Application of the weld strength model}

Using equations (1) and (2), weld strength was plotted and is shown in Fig. 6. The graph shows that the weld strength of specimens produced at contact pressures ranging between 241 and $276 \mathrm{kPa}$, an amplitude of $10.4 \mu \mathrm{m}$, and weld speeds of $34.5 \mathrm{~mm} / \mathrm{s}$ was greater than the strength of the base metal. The maximum weld strength was

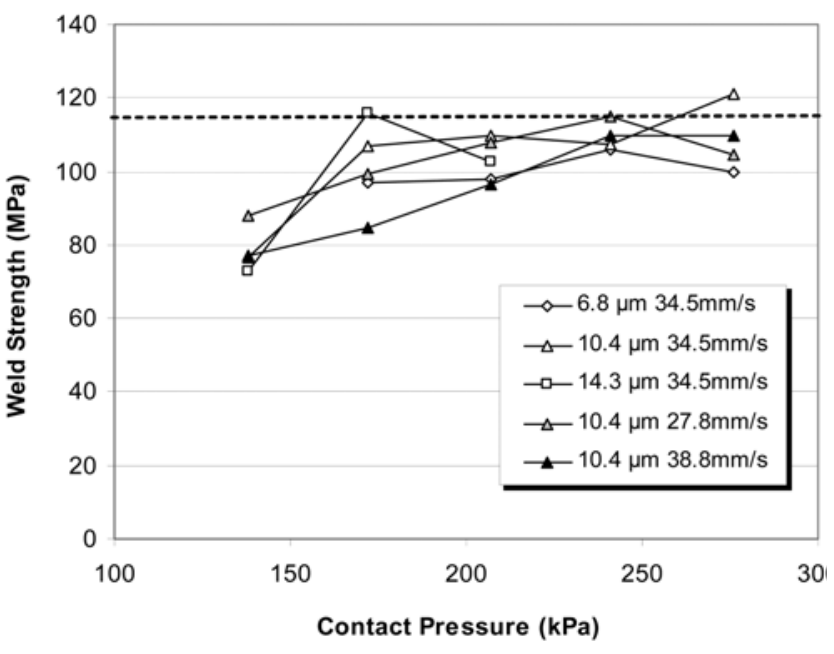

Fig. 6 Weld strength outcomes estimated using the theoretical model

122.8 MPa which was around 6.8 per cent higher than the strength of the base metal. Overall, weld strength increases with an increase in contact pressure and amplitude. Reducing the weld speed (at constant contact pressure and amplitude) increased the welding duration and delivered more ultrasonic energy to the workpiece. This is reflected in Fig. 6 where, at constant pressure and amplitude settings, average weld strength increased by around 15 per cent as weld speeds were reduced from 43.5 to $27.8 \mathrm{~mm} / \mathrm{s}$.

Figure 7 shows that weld strength may also be estimated by identifying the linear weld density and the contact pressure used. For example, a specimen with a linear weld density of 30 per cent and prepared using a contact pressure of $276 \mathrm{kPa}$ had an average weld strength of around $110 \mathrm{MPa}$ (depending on the amplitude setting and weld speed used, the

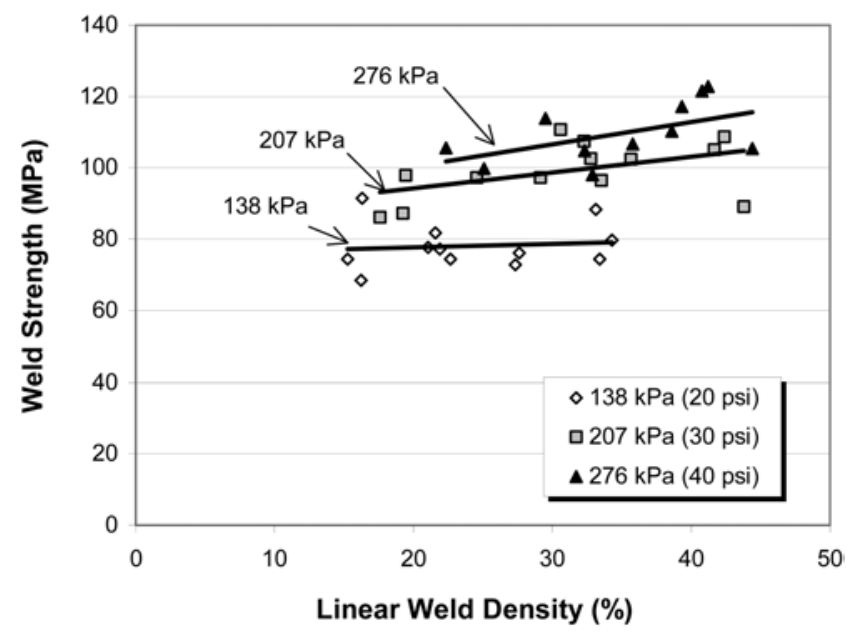

Fig. 7 Correlation of weld strength with linear weld density of welded specimens 
weld strength may be greater or lower than this figure).

\subsection{Relating increases in weld strength to microhardness across the weld interface}

Although there was no way to test for an increase in weld strength beyond the critical peeling load, it was possible to confirm the changes in weld strength at the interface by looking for increases in hardness, as predicted by the theory of surface and volume effects. Vickers microhardness readings were taken using cross-sectional samples through the bulk aluminium and into the weld interface, using the relationship between material hardness and strength, in terms of mechanical properties.
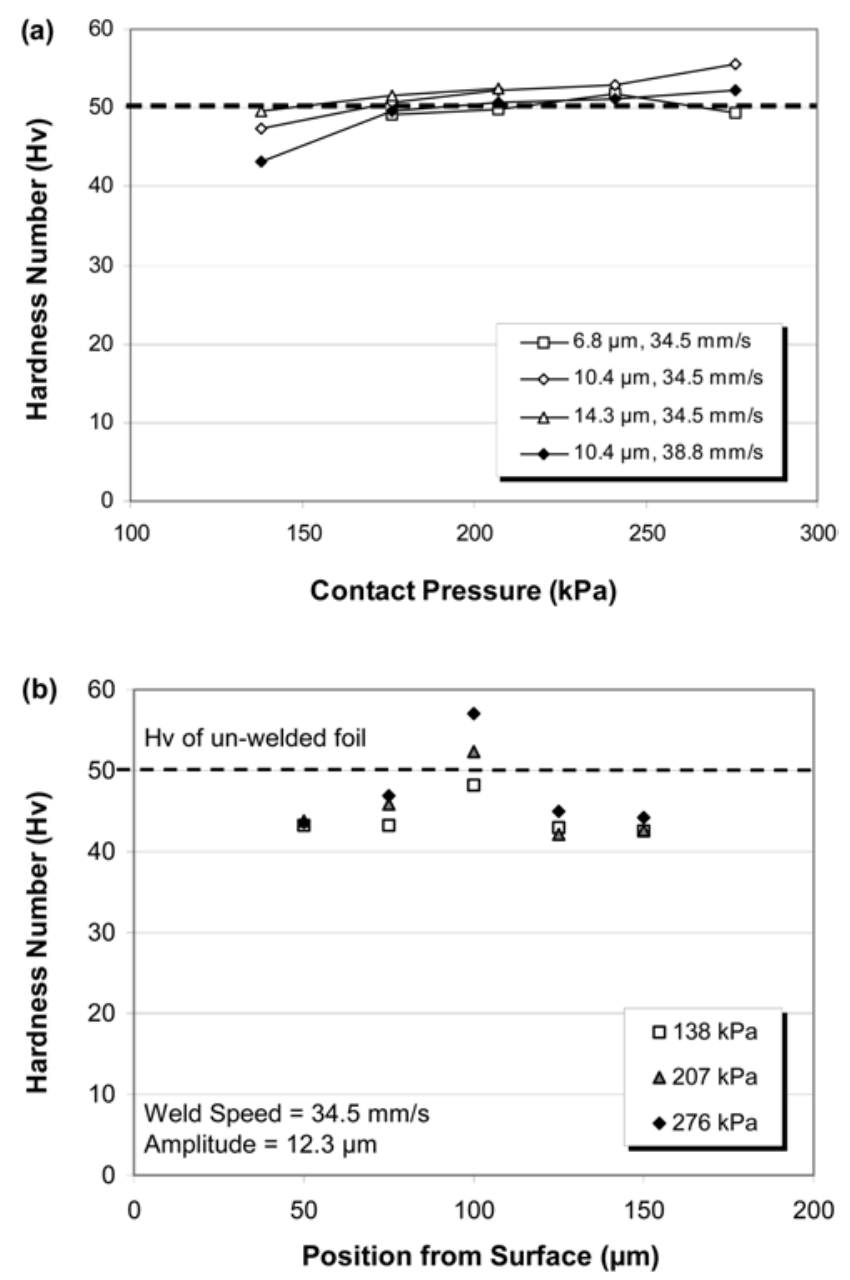

Fig. 8 Microhardness test results: (a) specimen hardness number against contact pressure; (b) distribution of hardness measurements in the welded specimen, showing that the weld interface (at $100 \mu \mathrm{m}$ from the surface) has higher HV compared with the surrounding regions
Measurements were taken by a Vickers diamond pyramidal indenter under a $50 \mathrm{~g}$ load for $15 \mathrm{~s}$ using a Buehler's Micromet 2100 microhardness tester. For each welded specimen, five measurements were taken at $50,75,100,125$, and $150 \mu \mathrm{m}$ respectively, with the position at $0 \mu \mathrm{m}$ being the uppermost face of the weld, i.e. the surface that makes direct contact with the sonotrode during welding. With a foil thickness of $100 \mu \mathrm{m}$, microhardness measurements for the weld interface were therefore $100 \mu \mathrm{m}$ below the surface. Six sets of measurements were recorded from three specimens welded using identical process parameters. The Vickers hardness number (HV) for each position was determined by averaging.

From the measurements, acoustic softening and hardening, as predicted by surface and volume effects, were observed, as shown in Fig. 8(a). The results were the average of microhardness values obtained from the weld interface $(100 \mu \mathrm{m}$ from the surface). Acoustic softening was observed in specimens welded at low contact pressures from 138 to $176 \mathrm{kPa}$, producing HV measurements less than the hardness value of the unwelded 6061 foil (shown as a dotted line at $\mathrm{HV}=50.16$ ). In contrast, specimens produced using a $276 \mathrm{kPa}$ contact pressure produced acoustic hardening at the weld interface, that hardness number being around 10 per cent greater than that of the unwelded foil.

As welding proceeds, dislocations move from the crystal lattice to the grain boundaries at the weld interface, leading to the acoustic hardening effect mentioned. By plotting microhardness in terms of the position of the measurement taken across the weld interface, Fig. $8 \mathrm{~b}$ shows that, for those measurements taken at 50, 75, 125, and $150 \mu \mathrm{m}$ from the surface, reduced hardness was

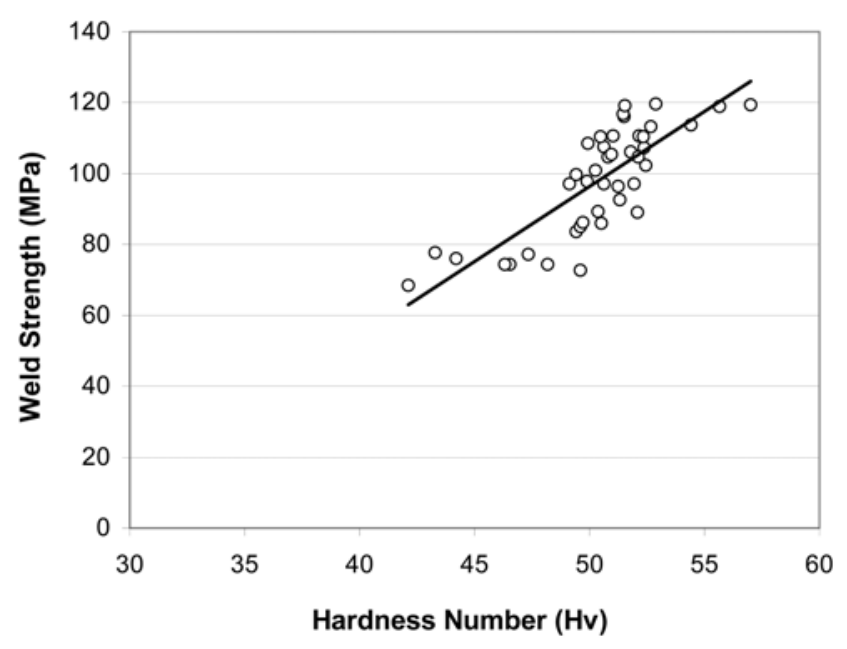

Fig. 9 Correlation of weld strength to hardness at the weld interface of the specimens 
present, after welding, compared with the hardness of unwelded foils.

By combining the results of the weld strength and the microhardness data in Fig. 9, a linear curve was obtained, confirming that, for increasing weld strength, the model shadowed the increase in microhardness. Where specimens were produced at low contact pressures, low amplitudes, and high weld speeds, low-strength welds were produced, as well as hardness measurements below $\mathrm{HV}=50.16$. At higher contact pressures, higher amplitudes, and lower weld speeds, the weld strength was equal to or greater than the strength of the base metal.

\section{CONCLUSIONS}

1. The standard method by which peel tests are used to identify weld strength in ultrasonic welds has been shown to have shortcomings as it is incapable of identifying weld strength above the tensile strength of the foils being welded. In such cases, specimens fail in the region of the foil adjacent to the weld, predominantly as the weld has greater strength than the single foil being peeled. Microstructural analysis has been shown to be capable of overcoming this limitation by measuring the proportion of 'contact points' within the weld interface. Of importance is that the method can show increases in the weld strength, though not quantifiable, above the point at which failure would occur in the peel test procedure.

2. The application of the 'theory of surface and volume effects' was necessary in order to understand how welds form, at the weld interface, and therefore how weld strength increases over the duration of the weld. Should strain hardening, due to the surface effect, and acoustic hardening, due to the volume effect, occur at the weld interface, there would be an increase in hardness and hence in weld strength that the peel test would not be able to measure.

3. A model has been described that (a) uses peel test data for each combination of process variables up to the point at which failure occurs in the base metal, occurs and (b) uses linear weld density data to show increases in weld strength at and above this point. The model therefore shows the effective increase in weld strength across a large range of process variables associated with the ultrasonic welding of 6061 alloy foils.

4. A series of Vickers microhardness tests have been conducted to validate whether acoustic softening and hardening were present in the weld interface, and also to show, by the association between hardness and weld strength, any increase in weld strength above the point at which the peel test would fail, as the model had predicted.

\section{ACKNOWLEDGEMENTS}

The authors would like to take the opportunity to thank the project partners Solidica Incorporated and the Engineering and Physical Sciences Research Council (EPSRC) for supporting this work.

\section{REFERENCES}

1 White, D. R. Ultrasonic consolidation of aluminium tooling. Advd Mater. and Processing, 2003, 161, 64-65.

2 Weare, N. E., Antonevich, J. N., and Monroe, R. E. Fundamental studies of ultrasonic welding. Weld. J., 1960, 39, 331s-341s.

3 Crinon, E. and Evans, J. T. The effect of surface roughness, oxide film thickness and interfacial sliding on the electrical contact resistance of aluminium. Mater. Sci. and Engng A, 1998, 242, 121-128.

4 Neppiras, E. A. Ultrasonic welding of metals. Ultrasonics, 1965, 3(3), 128-135.

5 Daniels, H. P. C. Ultrasonic welding. Ultrasonics, 1965, 3(4), 190-196.

6 Flood, G. Ultrasonic energy welds copper to aluminium. Weld. J., 1997, 76(1) 43-45.

7 Jones, J. B. and Powers, J. J. Ultrasonic welding. Weld. J., 1956, 35, 761-766.

8 Jones, J. B. and Meyer, F. R. Ultrasonic welding of structural aluminium alloys. Weld. J., 1958, 37(3), 81s-92s.

9 Kong, C. Y., Soar, R. C., and Dickens, P. M. An investigation of the control parameters for aluminium 3003 under ultrasonic consolidation. In Proceedings of 13th Solid Freeform Fabrication Symposium, Austin, Texas, August 2002, pp. 199-211.

10 Kong, C. Y., Soar, R. C., and Dickens, P. M. Characterisation of aluminium alloy 6061 for the ultrasonic consolidation process. Mater. Sci. and Engng A, 2003, 363, 99-106.

11 Holub, K. J. and Matienzo, L. J. Magnesium diffusion in several aluminium alloys. Applic. Surf. Sci., 1981, 9, $22-38$.

12 Lea, C. Oxidation of rolled and heat treated Al-Mg alloys. Applic. Surf. Sci., 1984, 17, 344-362.

13 Male, A. T. The effect of temperature on the frictional behaviour of various metals during metal working. J. Inst. Metals, 1964-65, 93, 489-494.

14 Riesz, C. H. Lubrication. In: Metal Deformation Processes (Ed. J. A. Schey), 1970, pp. 90-97 (Marcel Dekker, New York).

15 Winsper, C. E. and Sansame, D. H. The influence of oscillatory energy on the stress during plastic deformation. J. Inst. Metals, 1968, 96, 353-357.

16 Dawson, G. R., Winsper, C. E., and Sansome, D. H. Application of high- and low-frequency oscillations to the plastic deformation of metals. 1: metal forming, 1970, 37, 234. 
17 Dawson, G. R., Winsper, C. E., and Sansome, D. H. Application of high- and low-frequency oscillations to the plastic deformation of metals. 2: metal forming, 1970, 37, 254-261.

18 Severdenko, V. P., Klubovich, V. V., and Stepanenko, A. V. Ultrasonic Rolling and Drawing of Metals (Translated from Russian by E. H. Virden), 1972, pp. 43-50 (Consultant Bureau, New York).

19 Eaves, A. E., Smith, A. W., Waterhouse, W. J., and Sansome, D. H. Review of the application of ultrasonic vibrations to deforming metals. Ultrasonics, 1975, 13(4), 162-170.

20 Bowden, F. D. and Tabor, D. The Friction and Lubrication of Solids, 1950 (Oxford University Press, London).

21 Joshi, K. C. Formation of ultrasonic bonds between metals. Weld. J., 1971, 50(12), 840-848.
22 Langenecker, B. Effects of ultrasound on deformation characteristics of metals. IEEE Trans. Sonics and Ultrasonics, 1966, 13s(1), 1-8.

23 Bowden, F. D. A review of the friction of solids. Wear, 1957, 1(4), 333-346.

24 Hulst, A. P. Macrosonic in industry. 2: ultrasonic welding of metals. Ultrasonics, 1972, 10(6), 252-261.

25 Hansson, I. and Thölen, A. Plasticity due to superimposed macrosonic and static strains. Ultrasonics, 1978, 16(2), 57-64.

26 Madaah-Hosseini, H. R. and Kokabi, A. H. Cold roll bonding of 5754-aluminum strips. Mater. Sci. and Engng A, 2002, 335, 186-190.

27 Hatch, J. E. (Ed.) Aluminum - Properties and Physical Metallurgy, 1984, pp. 110-111 (American Society of Metals, Ohio). 